British Journal of Haematology, 1972, 22, 651 .

\title{
Defective Erythrocyte Pyruvate Kinase with Impaired Kinetics and Reduced Optimal Activity
}

\author{
Donald E. Paglia, William N. Valentine and Donald L. Rucknagel \\ with the technical assistance of MARY LU WIISON and JuLIE WITTENBERG \\ Departments of Medicine and Pathology, Center for the Health Sciences, University of \\ California, Los Angeles; Research and Medical Services, Veterans Administration Center, \\ Los Angeles, California; and Department of Human Genetics, \\ University of Michigan Medical School, Ann Arbor, Michigan
}

(Received 8 July $197 \mathrm{I}$; accepted for publication 19 October 197I)

\begin{abstract}
SUMmaRY. A unique mutant form of erythrocyte pyruvate kinase has been found associated with chronic haemolytic anaemia in a child who is apparently doubly heterozygous for the mutant isoenzyme and for pyruvate kinase deficiency of the classical quantitative type. Clinical and laboratory findings conformed closely to those typically observed in homozygous pyruvate kinase deficiency anaemia. Assayed in fresh haemolysates, the isoenzyme exhibited reduced optimal activity ( $c 45 \%$ of normal) and an increased Michaelis constant for phosphoenolpyruvate (four to five times greater than normal). The kinetic anomaly was only partially corrected by activation with fructose-I,6-disphosphate. Despite some common characteristics, this isoenzyme appears distinct from others reported in the literature and lends support to the polymorphous nature of heritable haemolytic anaemias secondary to defective pyruvate kinase.
\end{abstract}

Pyruvate kinase (PK) (ATP:pyruvate phosphotransferase, EC 2.7.I.40) catalyses the conversion of phosphoenolpyruvate (PEP) and adenosine diphosphate (ADP) to pyruvate and adenosine triphosphate (ATP). This constitutes a critical ATP regenerating reaction in mature human erythrocytes which must rely almost exclusively upon glycolysis to fulfil energy requirements. Homozygously inherited deficiency of the enzyme is often the only definable biochemical lesion in cases of congenital nonspherocytic haemolytic anaemia. No longer entirely tenable, it was the initial presumption that haemolysis occurred in such cases when the quantity of functional enzyme had been degraded to levels incompatible with effective glycolysis. More recent evidence indicates that abnormal isoenzymes of PK also exist which may be associated with haemolytic anaemia despite being highly active in vitro under optimal assay conditions. One such isoenzyme demonstrated markedly impaired kinetics with an elevated Michaelis-Menten constant $\left(K_{m}\right)$ for one of its substrates, PEP (Paglia et al, I968). It was postulated that this mutant enzyme might be as rate limiting in glycolysis as normal PK which was quantitatively deficient, since in both instances intracellular PEP concentrations would have to rise appreciably before effective catalysis could occur.

Correspondence: Dr Donald E. Paglia, Department of Pathology, Center for the Health Sciences, University of California, Los Angeles, California 90024, U.S.A. 
The present report summarizes clinical, haematologic and biochemical findings in another family which appears to be afflicted in a similar, yet clearly distinct manner. The maternal side harbours an abnormal PK isoenzyme of a type not previously reported. Heterozygous PK deficiency of the classical form exists in paternal relatives, including the father. By virtue of simultaneous inheritance of the paternal gene resulting in quantitatively deficient activity and the mutant maternal allele, the proband is presumed to have erythrocytes which contain, in effect, only the mutant isoenzyme. The latter was characterized by low optimal activity $\left(V_{\max }\right)$, elevated $K_{\mathrm{m}}(\mathrm{PEP})$, and an unusual response to the $\mathrm{PK}$ activator, fructose-I,6-diphosphate (FDP).

\section{Subjects}

\section{METHODS}

The proband was a 7-yr-old male of English-Irish ancestry who was born at full term following an uncomplicated pregnancy and delivery. Jaundice was apparent immediately, with bilirubin elevated to $6.3 \mathrm{mg} / 100 \mathrm{ml}$, of which $0.9 \mathrm{mg} / 100 \mathrm{ml}$ was direct-reacting. Haemoglobin was $1 \mathrm{I} .9 \mathrm{~g} / 100 \mathrm{ml}$, and there were 76 nucleated erythrocytes per 100 leucocytes. An exchange transfusion was performed on the first day of life, although no blood group antigen incompatibilities could be demonstrated.

The patient remained asymptomatic until the onset of pallor at the age of $\mathrm{I} \frac{1}{2} \mathrm{mth}$. At $3 \mathrm{mth}$ of age, $\mathrm{Hb}$ was $5.9 \mathrm{~g} / \mathrm{I00} \mathrm{ml}$, reticulocytes totalled $\mathrm{II.} . \%$, and there were 6 nucleated erythrocytes per roo leucocytes. Antiglobulin tests were negative. Autohaemolysis was increased and only partially corrected by glucose. Osmotic fragility studies and screening tests for G6PD, PK, and glutathione reductase deficiencies were also normal. Peripheral blood leucocytes totalled I4 50o/ $\mu \mathrm{l}$ with a normal differential count, and platelets appeared normal.

Infancy and early childhood were characterized by chronic haemolytic anaemia, occasional icterus, and progressive hepatosplenomegaly. Transfusions were required at 2-3 mth intervals when $\mathrm{Hb}$ levels fell to $c 5 \mathrm{~g} / \mathrm{I00} \mathrm{ml}$. Reticulocyte counts were generally elevated to $15-20 \%$. Haemoglobin electrophoresis and alkali denaturation showed 3.8-4.7\% $\mathrm{Hb} \mathrm{F}$ in the proband and no abnormal haemoglobins in the parents. By the age of $6 \mathrm{yr}$, the liver and spleen extended $3 \mathrm{~cm}$ and $10 \mathrm{~cm}$ below their respective costal margins. Height, weight and development remained within normal limits for his age.

Because of abdominal discomfort and indications of progressive hypersplenism, splenectomy was performed at the age of $6 \frac{1}{2} \mathrm{yr}$. A total of 9 l. of packed red cells had been given up to that point. Antiglobulin tests were still negative. The spleen weighed $800 \mathrm{~g}$ and was characterized by prominent red pulp with moderate littoral cell hyperplasia and scattered haemosiderin-laden macrophages. In the year following splenectomy, he required no further transfusions. Haemoglobin levels fluctuated between 9.2 and $10.4 \mathrm{~g} / \mathrm{IOO} \mathrm{ml}$, leucocytes between 6000 and II $900 / \mu 1$, and platelet counts were $c 540000 / \mu 1$.

There was no history of anaemia or jaundice in any blood relative, including an older sibling, and there was no evidence of consanguinity.

\section{Procedures}

Venous blood specimens from family members and normal controls were anticoagulated by heparin, refrigerated with ice, and shipped from Ann Arbor, Michigan, to Los Angeles 
for processing within $48 \mathrm{hr}$. Five-millilitre aliquots of fresh blood were also precipitated by immediate mixture with $10 \mathrm{ml} 0.6 \mathrm{~N}$ perchloric acid for determination of adenine nucleotide and glycolytic intermediate concentrations by the methods of Minakami et al (I965). A modification of Krimsky's (1963) method was used to measure 2,3-diphosphoglycerate.

To prepare cells for enzyme assays, heparinized specimens were mixed with $0.25 \mathrm{vol} 5 \%$ polyvinylpyrrolidone (Plasdone C, Antara Chemicals, General Aniline and Film Corp., Los Angeles, Calif.) and allowed to stand at room temperature. As erythrocytes settled, the supernate, containing mostly platelets and leucocytes, was aspirated free and preserved. Sedimented erythrocytes were washed once with 5 vol cold isotonic saline and centrifuged at $450 \mathrm{~g}$ for ro min. Packed erythrocytes were drawn into a sterile plastic syringe containing an equal volume of compressed nylon wool (FT-242, scrubbed nylon fibre, Fenwal Laboratories, Morton Grove, Ill.) and warmed in an incubator to $37^{\circ} \mathrm{C}$ for $30 \mathrm{~min}$, with periodic remixing of the contents by rotation. This allowed most remaining granulocytes to contact and adhere to nylon fibres, yielding red cell preparations minimally contaminated with leucocytes. After incubation, erythrocytes were discharged from the syringe and washed twice with to vol cold isotonic saline, and centrifuged at $450 \mathrm{~g}$ for to min after each wash. Packed cells were diluted with saline to final concentrations of $c 3 \times 10^{6} / \mu$ l. Exact concentrations were determined by quadruplicate measurements with a Coulter Model F Counter, and the number of remaining leucocytes in each red cell preparation was determined by duplicate haemocytometer counts.

Leucocytes in the supernate preserved from the initial sedimentation procedure were similarly packed, washed twice with $30 \mathrm{ml}$ cold isotonic saline, and centrifuged as before. Washed leucocytes, now virtually free of platelets but variably contaminated with erythrocytes, were diluted with saline to $c 4 \times 10^{4} / \mu 1$. Final counts were determined in quadruplicate with the Coulter Counter.

Enzyme assays were performed using fresh cell lysates prepared by dilution in buffered saline or water and thrice frozen and thawed with a Dowanol and solid $\mathrm{CO}_{2}$ freezing bath. Assays of glycolytic, pentosephosphate pathway and ancillary enzymes were performed by procedures delineated elsewhere (Koutras et al, 1964; Schneider et al, 1965; Valentine et al, 1967, 1969, I970; Paglia \& Valentine, I967; Baughan et al, 1968).

Pyruvate kinase activity was determined by the method of Bücher \& Pfleiderer (1955) as modified in a previous report (Valentine \& Tanaka, 1966). The standard assay system employed 2.0 mM PEP, 0.4 mM ADP, 8.0 $\mathrm{mM} \mathrm{MgSO}_{4}$, $0.2 \mathrm{~mm}$ reduced nicotine adenine dinucleotide (NADH), 6 units/ml lactate dehydrogenase $(\mathrm{LDH})$, and $75 \mathrm{mM} \mathrm{KCl}$ in $8.3 \mathrm{~mm}$ triethanolamine hydrochloride buffer at a final $\mathrm{pH}$ of $7.2 \pm 0.1$. An identical system containing only 0.4 mM PEP was assayed simultaneously. Pyruvate formed from PEP by the PK reaction was immediately converted to lactate by the crystalline LDH with consequent oxidation of $\mathrm{NADH}$. The latter was observed by monitoring the time sequence of absorbence changes at $340 \mathrm{~m} \mu$ using a Gilford multiple sample absorbence recorder, Model 2000. Reagent blanks devoid of haemolysate were assayed at each PEP concentration used, and the resultant values (usually almost negligible) were subtracted from activities observed in complete systems. Enzyme units $(u)$ were defined as the number of micromoles of NADH oxidized each minute by $10^{10}$ cells at $37^{\circ} \mathrm{C}$.

Apparent PK Michaelis constants for PEP were determined at two different concentrations 
of ADP, 0.4 and I.o mM. Phosphoenolpyruvate concentration was varied between $0 . \mathrm{I}$ and I0.0 mM. Michaelis constants for ADP were measured using 2.0 mM PEP and ADP concentrations between 0.1 and ro. $\mathrm{mM}$. Values for $K_{\mathrm{m}}$ were obtained by extrapolation of twelvepoint Wolff plots and confirmed by determination of substrate concentrations coinciding with half maximal activities by direct reading of best-fit linear coordinate curves.

\section{RESULTS}

\section{Haematologic Studies}

Haematologic values obtained on family members during the $9 \mathrm{mth}$ study period are summarized in Table I. The proband was persistently anaemic despite periodic transfusions

TABLE I. Mean haematologic measurements on shipped specimens: kindred C

\begin{tabular}{|c|c|c|c|c|c|}
\hline Subject & $\begin{array}{c}H b \\
(g / 100 \mathrm{ml})\end{array}$ & $\begin{array}{l}P C V \\
(\%)\end{array}$ & $\begin{array}{c}R B C \\
\left(\times 10^{6} / \mu l\right)\end{array}$ & $\begin{array}{c}\text { Reticulocytes } \\
(\%)\end{array}$ & $\begin{array}{c}W B C \\
(\mid \mu l)\end{array}$ \\
\hline $\begin{array}{l}\text { Proband (III-2)* } \\
\text { Mother (II-3) } \\
\text { Father (II-2) } \\
\text { Brother (III-I) } \\
\text { Paternal aunt (II-I) } \\
\text { Maternal uncle (II-4) } \\
\text { Maternal grandmother (I-4) } \\
\text { Paternal grandmother (I-2) } \\
\text { Paternal grandfather (I-I) }\end{array}$ & $\begin{array}{r}6.9 \\
12.5 \\
17.0 \\
14.7 \\
15.0 \\
14.4 \\
13.5 \\
15.2 \\
13.5\end{array}$ & $\begin{array}{l}21 \\
36 \\
49 \\
4 I \\
47 \\
43 \\
39 \\
45 \\
38\end{array}$ & $\begin{array}{l}2.06 \\
3.98 \\
5.48 \\
4.82 \\
5.19 \\
4.74 \\
4.26 \\
5.16 \\
4.18\end{array}$ & $\begin{array}{r}10.9 \\
1.2 \\
1.3 \\
1.3 \\
1.2 \\
0.4 \\
1.2 \\
0.7 \\
0.8\end{array}$ & $\begin{array}{l}1730 \\
5750 \\
4620 \\
3175 \\
7360 \\
5060 \\
4170 \\
5600 \\
5485\end{array}$ \\
\hline
\end{tabular}

* Genealogy designation according to Fig 6.

and consistent reticulocytosis, but anaemia was not apparent in any relative. Low levels of peripheral leucocytes had been a common finding in this patient for almost $4 \mathrm{yr}$, and platelet counts were also slightly reduced during this period. The proband's erythrocytes exhibited moderately severe anisopoikilocytosis with frequent schistocytes and pyknocytes. Leucocyte morphology and differential counts were normal.

\section{Glycolytic Intermediates and Adenine Nucleotides}

Peripheral blood concentrations of glycolytic intermediates were measured in the patient and his parents and found to be normal in the latter. In the proband's specimens, however, marked elevations of some intermediates were demonstrable, most prominently the phosphoglycerates, PEP, and hexosemonophosphates, which were three to five times normal mean levels. The pattern of intermediate elevations was remarkably similar to that seen in classical homozygous PK deficiency as shown in Fig I, which demonstrates further that these changes were not simply a consequence of reticulocytosis. Blood ATP concentrations were reduced in the proband, and the ATP/ADP ratio was reversed.

Erythrocyte Enzyme Activities

Fig 2 presents relative profiles of various enzyme activities in freshly prepared crude 
haemolysates. Elevated catalytic rates in proband haemolysates correlated well with the activity increases characteristic of specimens with young mean cell ages. The notable exception was PK, which approximated $40 \%$ of normal mean activities and only $20 \%$ of that expected in a specimen with this degree of reticulocytosis. The only abnormality in parental enzyme activities was a similar reduction of PK to $40-60 \%$ of normal rates. Activity decrements of this magnitude are generally found in heterozygous PK deficiencies, which are

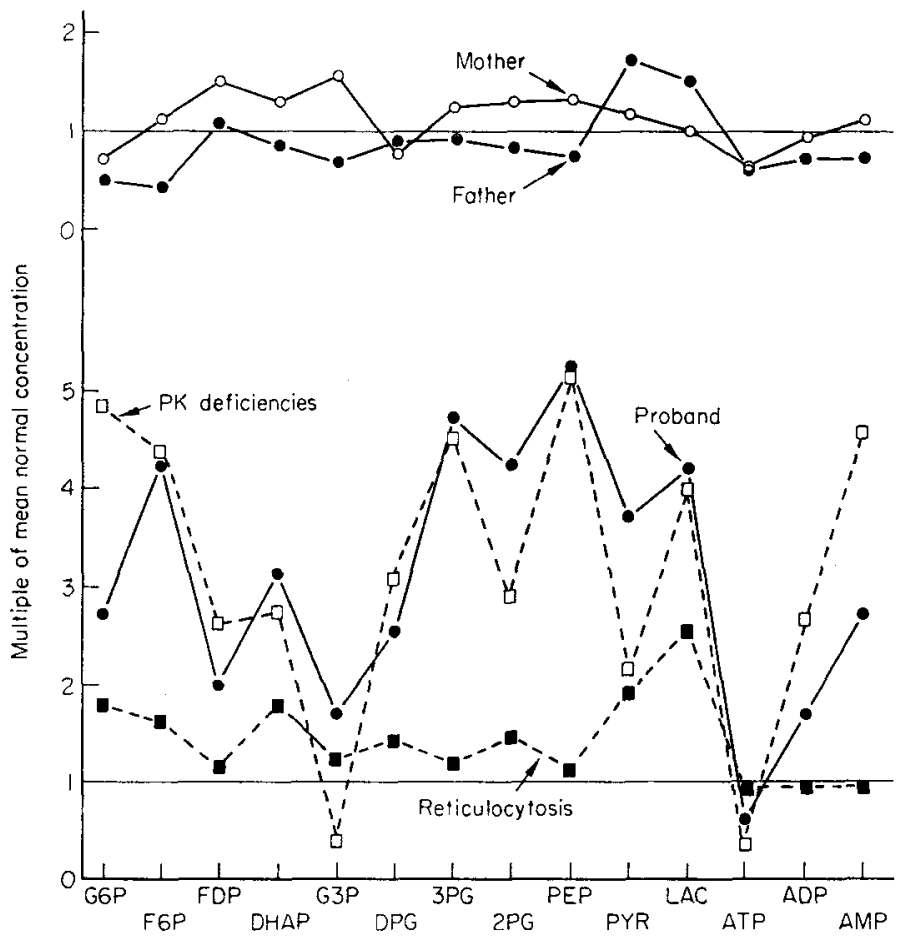

FIG I. Relative concentrations of peripheral blood glycolytic intermediates and adenine nucleotides. Mean laboratory values for normal subjects are represented by the horizontal line at a multiple of $I$. Broken curves, labelled 'PK deficiencies' ( $\square$ ) and 'Reticulocytosis' ( $\square$ ) respectively, represent mean values from simultaneous assays of two cases with classical homozygous PK deficiency anaemia and from six cases with a mean reticulocyte count of $8.8 \%$ induced by causes other than erythroenzymopathies. Compounds abbreviated along the abscissa are in order: glucose-6-phosphate, fructose-6phosphate, fructose-1,6-disphosphate, dihydroxyacetone phosphate, glyceraldehyde-3-phosphate, 2,3-diphosphoglycerate, 3-phosphoglycerate, 2-phosphoglycerate, phosphoenolpyruvate, pyruvate, lactate, and adenosine triphosphate, diphosphate and monophosphate.

almost always devoid of accelerated haemolysis. By comparison, $V_{\max }$ in anaemic patients with homozygous deficiency is usually less than $20 \%$ of normal mean.

Activities at 2.0 mM PEP are a close reflection of PK $V_{\max }$ for normal erythrocytes under these assay conditions. As shown in Table II, all members of the immediate family, as well as the paternal grandmother and aunt, had values compatible with heterozygous PK deficiency. Activities were marginal in some relatives, but were interpretable with greater certainty when compared with their accompanying controls.

Measurement of PK activities both at low and high substrate concentrations (e.g. 0.4 and 
2.0 $\mathrm{mm}$ PEP) has been found to be a useful screening technique for detection of kinetic abnormalities (Paglia et al, 1968). Ratios of activities at these two concentrations are consistently greater than 0.7 with normal PK and may be reduced below 0.2 for some mutant forms of PK which are incapable of catalysing effectively under conditions of low substrate availability. Applying this index, the proband's activity ratio of 0.50 was found to be distinctly abnormal, as was the maternal value of 0.55 , suggesting the presence of anomalous PEP kinetics. Ratios for all other family members were within normal limits.

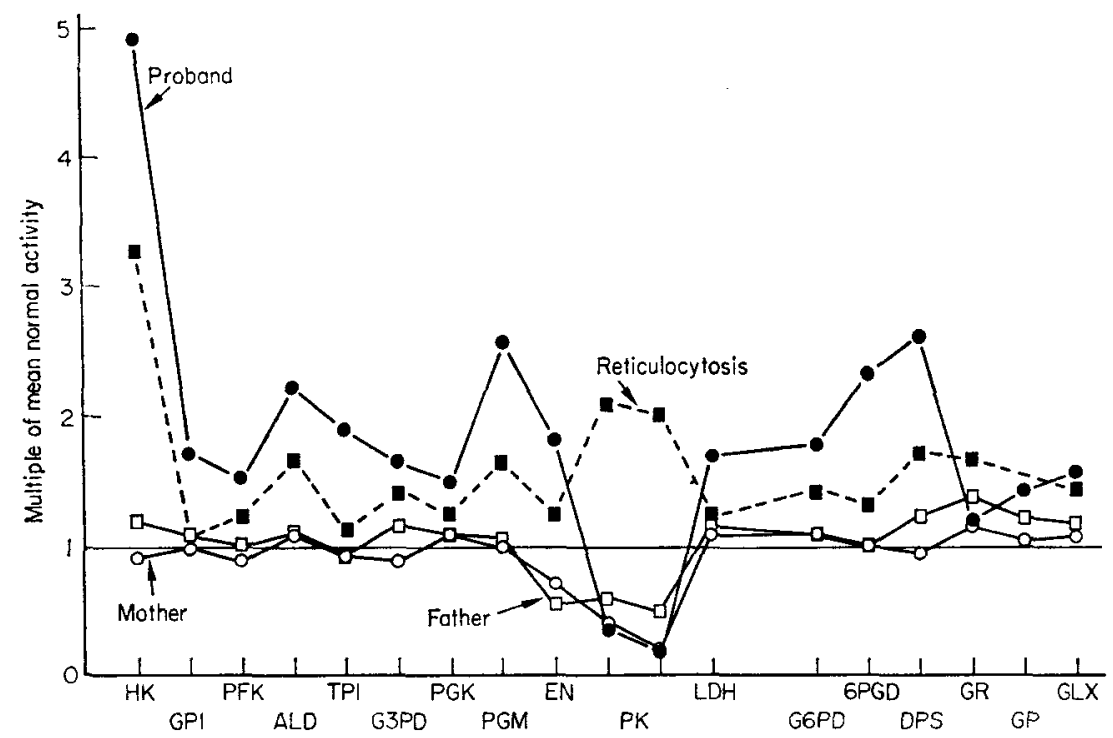

FIG 2. Relative activies of various erythrocyte enzymes. Mean laboratory values for normal subjects are represented by the horizontal line at a multiple of $I$. The broken curve labelled 'Reticulocytosis' describes mean values derived from 17 cases of haemolytic anaemia exclusive of erythroenzymopathies with a mean reticulocyte count of $11.2 \%$. Enzymes abbreviated along the abscissa are in order: hexokinase, glucosephosphate isomerase, phosphofructokinase, aldolase, triosephosphate isomerase, glyceraldehyde-3-phosphate dehydrogenase, phosphoglycerate kinase, 3-phosphoglyceromutase, enolase (phosphopyruvate hydratase), pyruvate kinase (assayed at $2.0 \mathrm{mM}$ PEP and at $0.4 \mathrm{mM}$ PEP), lactate dehydrogenase, glucose-6-phosphate dehydrogenase, 6-phosphogluconate dehydrogenase, combined enzymes of the distal pentosephosphate pathway, glutathione reductase, glutathione peroxidase and glyoxalase.

Fructose-I,6-diphosphate Effect in Standard PK Assay System

Significant activation of both proband and control PK activities was apparent over a broad range of FDP concentrations when availability of PEP was suboptimal (Fig 3). The two isoenzymes responded to variable FDP concentrations in a similar manner under these conditions, but the magnitude of response was considerably greater for proband PK. Concentrations greater than I mM FDP may induce inhibition of PK activity. Consequently, the concentration of 0.I mM FDP was selected to provide optinal activation of both normal and mutant isoenzymes for comparative purposes.

Addition of $0.1 \mathrm{mM}$ FDP to the standard assay system slightly enhanced PK activities at 2.0 $\mathrm{mM}$ PEP with disproportionately larger increases evident at $0.4 \mathrm{mM}$ PEP (Table II). It 


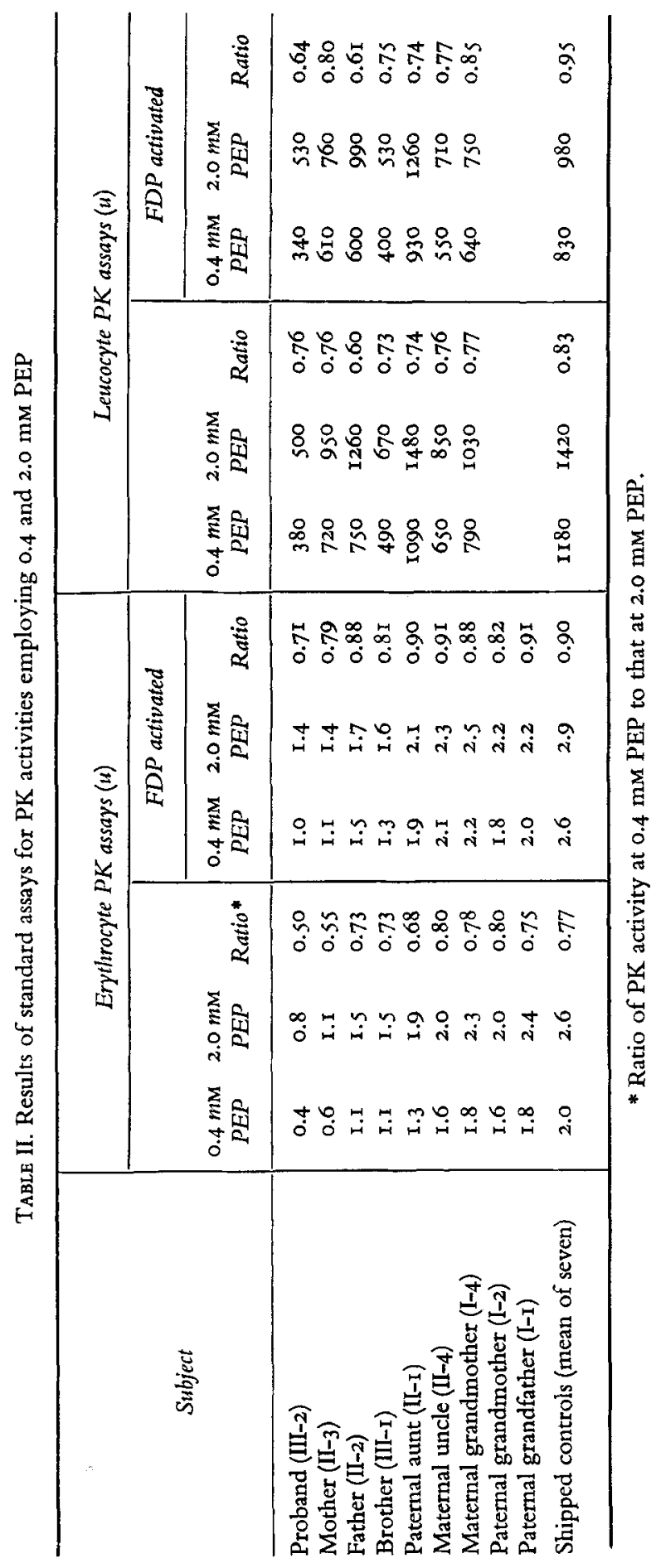


was notable, however, that proband and maternal values at the higher substrate concentration were increased approximately $40 \%$ by the activator, while increases in all other instances more closely approximated $10 \%$. The overall effect in each case was to alter activity ratios upward toward more clearly normal values.

Leucocyte PK determinations are subject to considerably more variation, normals in our laboratory ranging from $c 750 \mathrm{u}$ to $2100 \mathrm{u}$. Values included in Table II indicate that proband activities were marginally low, but this did not appear to be a significant deviation and may have been a reflection of contamination of the white cell preparations with nucleated erythrocytes. FDP had no apparent activation effect on PK in white cell lysates from any of the

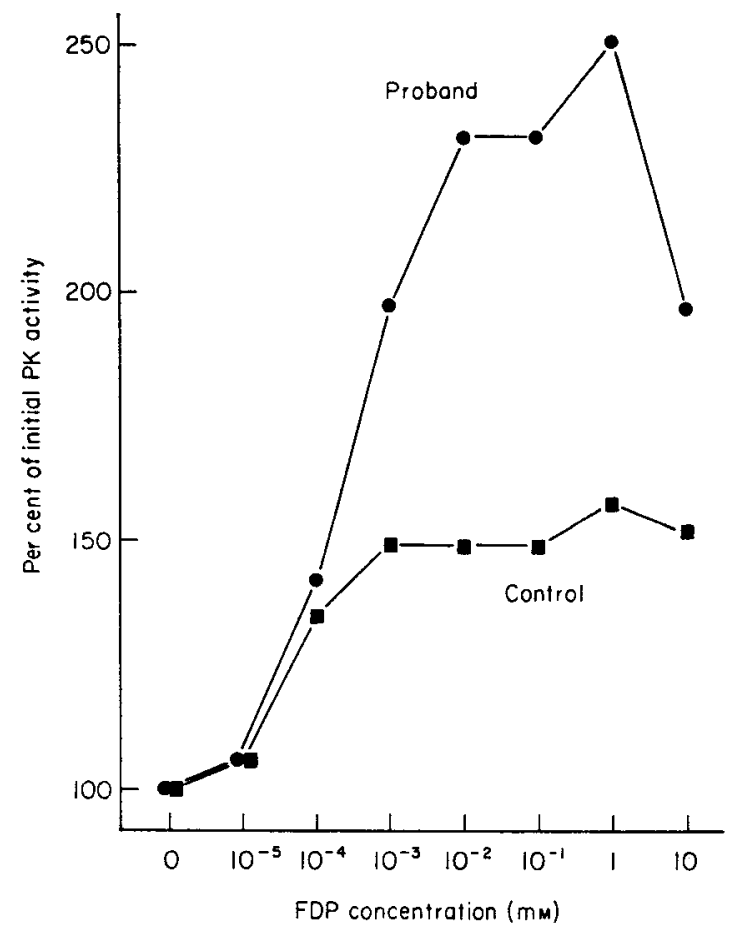

FIG 3. PK activation by varying concentrations of fructose-1,6-diphosphate in haemolysates from the proband and a normal control. To accentuate FDP activation, assays were performed using $2.0 \mathrm{mM}$ ADP and a suboptimal concentration of PEP ( $0.4 \mathrm{~mm})$.

subjects studied, and addition of FDP to the reaction medium seemed to result in somewhat lessened PK activities.

\section{Kinetics of Erythrocyte Pyruvate Kinase}

Kinetic curves characteristic of PK in proband and parental haemolysates are presented in Fig 4. For comparative purposes, a mean curve derived from accompanying control specimens is included. Usually, rapid increases in reaction rates are observed with only slight elevations in substrate concentration until $V_{\max }$ is achieved at 1.0-2.0 mM PEP. In sharp contrast, the proband curve was markedly skewed by a prolonged ascending limb. $V_{\max }$ was less than half normal mean values and was not reached until PEP concentration was $c 5$ mM. The maternal curve was similar to that of the proband, but activities at corresponding 
substrate levels were uniformly higher and $V_{\max }$ may have been achieved somewhat sooner (3-4 $\mathrm{mM}$ PEP).

Kinetics in paternal haemolysates more closely approximated those of subjects with classical heterozygous PK deficiency. $V_{\max }$ was slightly over half normal mean, but there was no impairment of activity with substrate deprivation as in the case of the proband and his mother.

Kinetic curves were developed for other relatives and their corresponding controls, affording more accurate determinations of $V_{\max }$ and apparent $K_{\mathrm{m}}$ (PEP) in each instance. Table III records mean $K_{\mathrm{m}}$ (PEP) obtained from Wolff plots and confirmed by linear coordinate curves. Michaelis constants were interpretable as normal in all family members

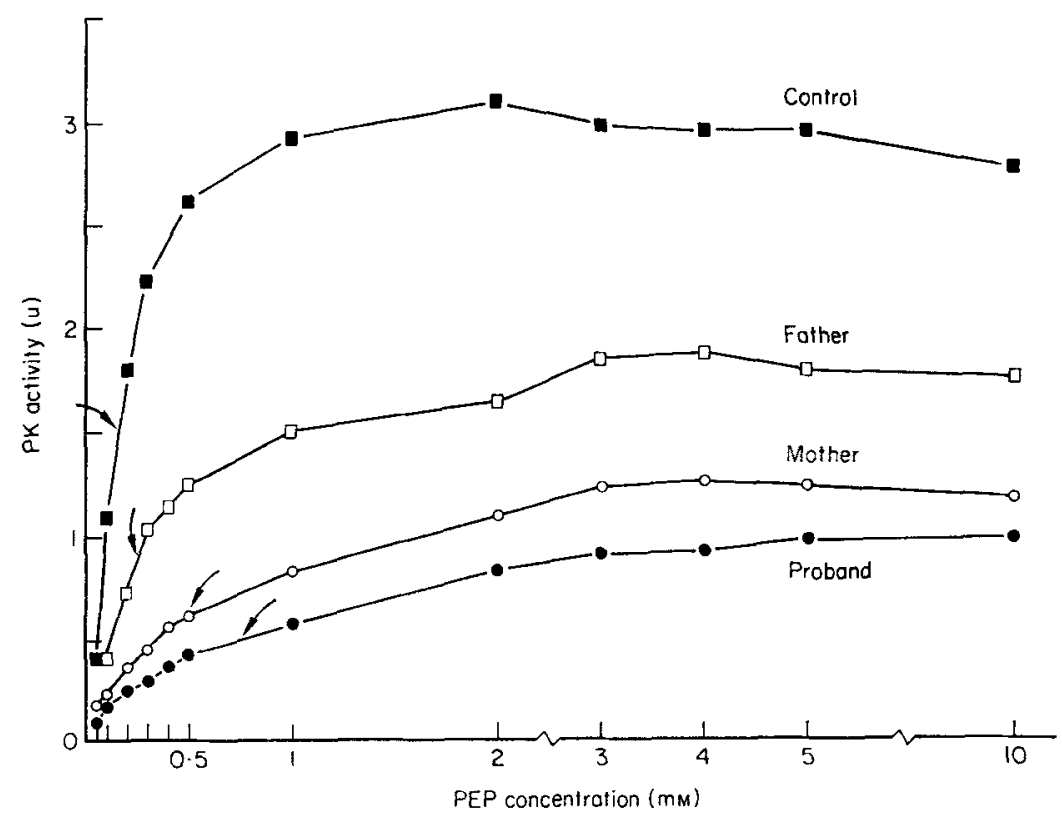

FIG 4. PK kinetic curves with PEP as the variable substrate. Arrows indicate points of half maximal $\mathrm{PK}$ activities which correspond to $K_{\mathrm{m}}(\mathrm{PEP})$ values on the abscissa.

except the proband and his mother in whom significant elevations occurred. The maternal value was intermediate between those of the proband and normals. An uncle and grandmother were the only other maternal relatives available for study, and their $K_{\mathrm{m}}$ (PEP) values were normal.

Optimal PK activities, defined by kinetic curve plateaus, were unequivocally normal only in the paternal grandfather and maternal grandmother. All members of the immediate family displayed $V_{\max }$ values lowered into the range associated with classical heterozygous PK deficiency, i.e. $c 50 \%$ of mean normal activity. Values which were marginally low were obtained on specimens from the paternal aunt and grandmother, but these two subjects were more convincingly deficient when compared with normal control specimens shipped and processed simultaneously.

Erythrocyte PK kinetic curves for PEP were redetermined with ADP concentration 
TABLE III. Maximum PK reaction velocities and Michaelis constants for phosphoenolpyruvate

\begin{tabular}{|c|c|c|c|c|}
\hline \multirow{2}{*}{ Subject } & \multicolumn{2}{|c|}{$V_{\max }(u)$} & \multicolumn{2}{|c|}{$K_{\mathrm{m}}(P E P)(m \mathrm{M})$} \\
\hline & & $\begin{array}{c}F D P \\
\text { activated }\end{array}$ & & $\begin{array}{c}F D P \\
\text { activated }\end{array}$ \\
\hline Proband (III-2) (mean of five) & I. 2 & 2.0 & 0.82 & 0.42 \\
\hline Mother (II-3) & 1.3 & x.6 & $0.5 \mathrm{I}$ & 0.19 \\
\hline Father (II-2) & I. 6 & 1.7 & 0.18 & 0.07 \\
\hline Brother (III-I) & I.S & I. 7 & 0.20 & 0.06 \\
\hline Paternal aunt (II-I) & 2.1 & 2.5 & 0.25 & 0.09 \\
\hline Maternal uncle (II-4) & 2.I & 2.4 & 0.17 & 0.06 \\
\hline Maternal grandmother (I-4) & 2.3 & 2.6 & 0.15 & 0.08 \\
\hline Paternal grandmother (I-2) & $2 . I$ & 2.3 & 0.11 & 0.07 \\
\hline Paternal grandfather (I-I) & 2.4 & 2.4 & 0.17 & 0.06 \\
\hline Shipped controls (mean of six) & 2.7 & 2.9 & 0.17 & 0.08 \\
\hline Normal controls (mean of 29 ) & 2.7 & 3.0 & 0.18 & 0.07 \\
\hline Standard deviation & 0.4 & 0.4 & 0.04 & 0.01 \\
\hline
\end{tabular}

elevated to I.o mM. Both $V_{\max }$ and $K_{\mathrm{m}}$ (PEP) values were uniformly elevated to almost twice those obtained using $0.4 \mathrm{mM} A D P$, but the distinctions among proband, kindred and normals remained unaltered.

\section{Fructose-I,6-diphosphate Effect on Pyruvate Kinase Kinetics}

As shown in Fig 5, addition of 0.I mM FDP to the reaction system enhanced the activity of normal PK most prominently when PEP availability was restricted. This occurs whether

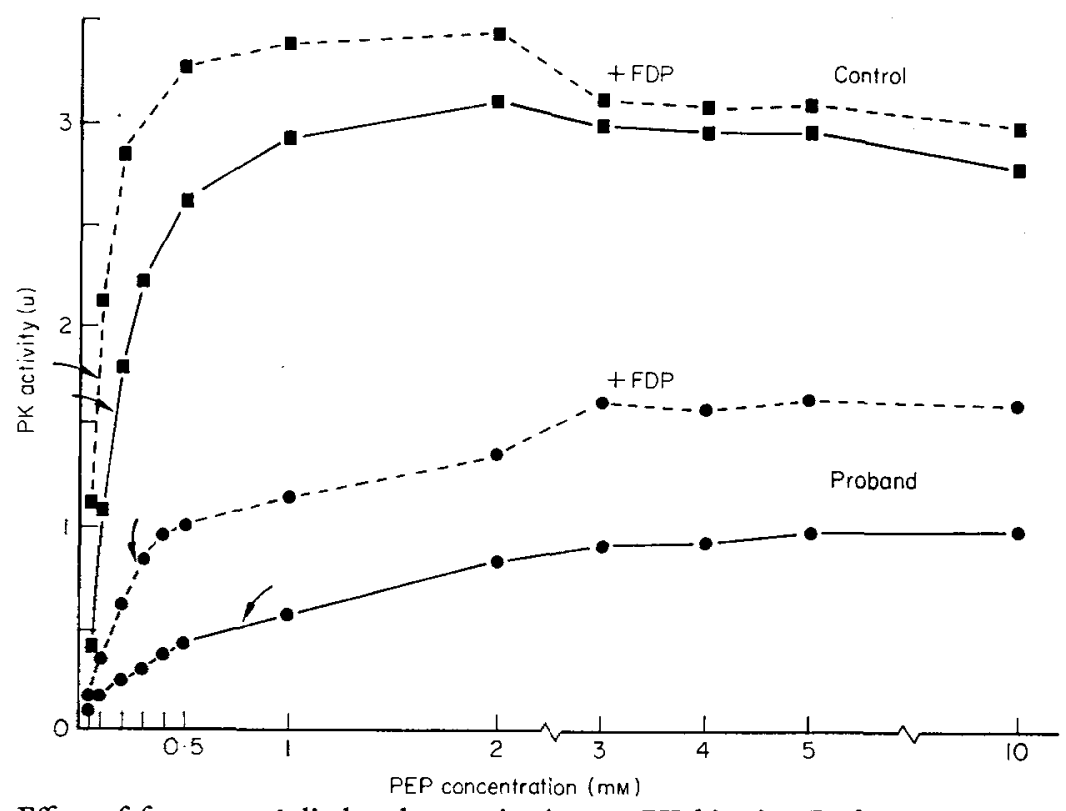

FIG 5. Effect of fructose-I,6-disphosphate activation on PK kinetics. Broken curves were derived from identical hacmolysates assayed simultaneously in the presence of o.I mM FDP. Arrows denote points of half maximal $\mathrm{PK}$ activity and $K_{\mathrm{m}}$ (PEP). 
the red cells under study are obtained from normal controls or from subjects with classical homozygous or heterozygous PK deficiency. Activation by FDP is less pronounced at higher PEP concentrations, thereby elevating $V_{\max }$ only slightly (IO-1 $5 \%$ ). The resultant kinetic effect is to decrease $K_{\mathrm{m}}$ (PEP) by $c 50 \%$ (Table III).

PK in haemolysates from all subjects studied conformed to this expected pattern of kinetic behaviour, except in those from the proband and perhaps his mother as well. In the presence of FDP, proband $V_{\max }$ increased more appreciably $(70 \%)$, and $K_{\mathrm{m}}(\mathrm{PEP})$ was reduced by $50 \%$ but remained distinctly abnormal ( $0.42 \mathrm{mM}$ ). Maternal PK $V_{\max }$ increased almost $25 \%$, and $K_{\mathrm{m}}(\mathrm{PEP})$ decreased to an intermediate value of $0.19 \mathrm{~mm}$.

\section{Erythrocyte Pyruvate Kinase Kinetics for Adenosine Diphosphate}

No abnormalities of $K_{\mathrm{m}}$ (ADP) were found, but distinctions between normal and kindred $V_{\max }$ values were accentuated when ADP served as the variable substrate (Table IV). Compared with means of normal controls assayed simultaneously, parental $V_{\max }$ was lowered to

TABLE IV. Maximum PK reaction velocities and Michaelis constants for adenosine diphosphate

\begin{tabular}{|c|c|c|c|c|}
\hline \multirow{2}{*}{ Subject } & \multicolumn{2}{|c|}{$V_{\max }(u)$} & \multicolumn{2}{|c|}{$K_{\mathrm{m}}(A D P)(n \mathrm{M})$} \\
\hline & & $\begin{array}{c}F D P \\
\text { activated }\end{array}$ & & $\begin{array}{c}F D P \\
\text { activated }\end{array}$ \\
\hline Proband (III-2) & I.I & 2.0 & 0.17 & 0.22 \\
\hline Mother (II-3) & $\mathbf{I} .8$ & 2.4 & 0.26 & 0.26 \\
\hline Father (II-2) & 2.6 & $3 \cdot 3$ & 0.30 & 0.40 \\
\hline Shipped controls (mean of four) & 4.8 & 4.9 & 0.34 & 0.30 \\
\hline
\end{tabular}

about one-half and that of the proband to one-fourth. Differences in FDP effect on $V_{\max }$ were also amplified. Normal PK activity was increased only slightly in the presence of the activator, whereas proband $\mathrm{PK}$ activity virtually doubled. Activation of maternal PK was again intermediate in degree. FDP had no appreciable effect on $K_{\mathrm{m}}$ (ADP) for any of the subjects studied.

\section{DISCUSSION}

Whether considered from a clinical or a molecular viewpoint, it has become progressively more certain that PK deficiency anaemias encompass a heterogeneous group of inherited defects. Phenotypic expression has been noted to vary considerably among different families and also among affected persons within the same family (Tanaka \& Valentine, 1968). The cases reported by Zuelzer et al (1968) were especially notable in this regard, with severely affected propositi and clinically normal relatives all demonstrating comparable levels of PK activity compatible with homozygous deficiency. A broad spectrum of expression has been noted not only for clinical severity but also for biochemical characteristics such as intracellular ATP, ATP stabilitics, glycolytic intermediates, NAD/NADH ratios, glucose consumption, and lactate production (Keitt, 1966).

The present case is typical of an expanding group which exhibits virtually all the clinical 
and laboratory features commonly associated with homozygous PK deficiency except for the critical finding of normal or intermediately depressed PK activity on biochemical assay. Specifically, the patient had a lifelong history of chronic haemolytic anaemia and splenomegaly without evidence of spherocytosis, antiglobulin reactions, or haemoglobinopathies. Erythrocyte osmotic fragility was normal, but autohaemolysis was elevated in a manner conforming to the Type II category of Selwyn \& Dacie (I954). Increased concentrations of glycolytic intermediates were typical of those commonly found in erythrocytes with defective PK catalysis, as were reductions in cellular ATP and concomitant increases in ADP. Further, erythrocyte PK activities in both parents and several relatives were approximately half normal.

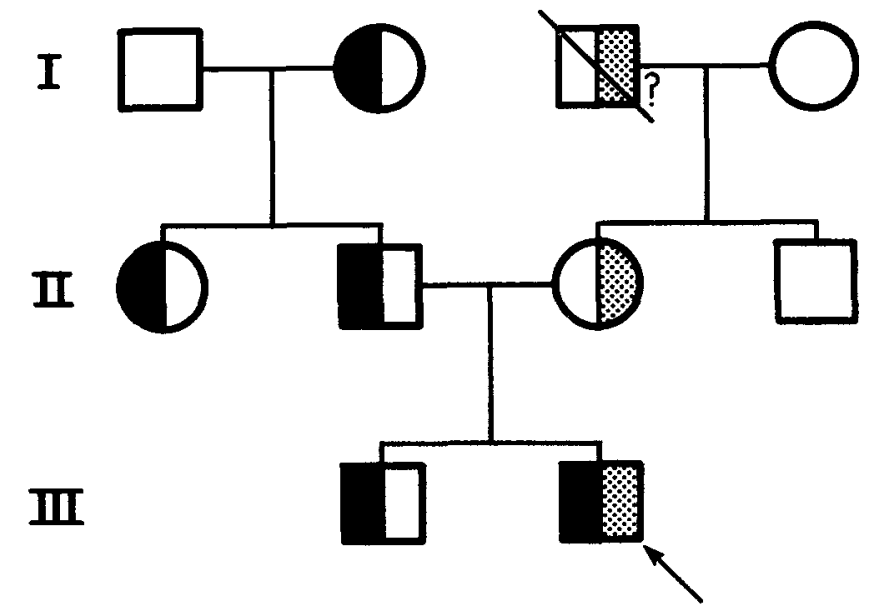

Fig 6. Genealogy of kindred C. The proband is marked by an arrow. Males and females are indicated by squares and circles, respectively. Heterozygosity for quantitative PK deficiency of the usual type is noted by partially blackened symbols. Shading indicates heterozygosity for the mutant allele. The maternal grandfather $(\mathrm{I}-3)$ is deceased and only presumed to be a heterozygote for the mutant isoenzyme.

Despite these similarities to quantitative PK deficiency anaemia, assays of proband haemolysates failed to reveal activity reductions sufficient in magnitude to support the diagnosis. Instead of expected depressions to $c 10 \%$ of normal mean activities, proband $V_{\max }$ values more closely approximated $40 \%$. Kinetic studies, however, established the unique nature of PK in proband erythrocytes, revealing markedly impaired catalysis when PEP was progressively diluted. The Michaelis constant for this substrate was elevated to five times the normal mean value. Kinetics for the other substrate, ADP, were unaltered, suggesting that the mutational change in the enzyme affected only the PEP binding site. PEP kinetics intermediate between normal and proband were demonstrable in the mother, whereas the father and all other relatives studied appeared entirely normal on this basis.

These findings were consistent with the presence of two distinct genes for erythrocyte PK in this family. Paternal relatives were affected with heterozygous PK deficiency of the usual quantitative type with half normal $V_{\max }$ values and totally normal kinetics, a defect identifiable in three generations (Fig 6). The mother (and presumably the deceased maternal grandfather) had PK characteristics suggestive of heterozygosity for normal PK and the mutant isoenzyme: moderately elevated $K_{\mathrm{m}}(\mathrm{PEP})$ and slightly reduced $V_{\max }$. 
The PK complement of proband cells was apparently limited in large measure to the mutant isoenzyme, characterized by markedly elevated $K_{\mathrm{m}}$ (PEP) and moderately reduced $V_{\max }$. This is assumed to result from simultaneous inheritance of the paternal gene determinant of quantitative deficiency and the mutant maternal allele. The ultimate effect, induction of premature haemolysis, seems most likely to be a consequence of ineffective catalysis by the mutant isoenzyme at the low PEP concentrations usually prevalent within erythrocytes. Phenotypic expression is thus identical with that which results from severe quantitative decreases in normal enzyme, since both essentially produce the same perturbation in glycolysis and impairment of ATP regeneration.

We are unaware of reported instances of PK isoenzymes which were clearly identical with that in the present case and presume that this simply represents one more example of molecular polymorphism characteristic of this erythroenzymopathy. Several mutant forms have now been identified which vary significantly in their kinetics and responses to FDP activation and additionally in such properties as $\mathrm{pH}$ optima, stabilities, and electrophoretic mobilities (Tanaka \& Paglia, 197I). Several cases have exhibited comparable increases in $K_{\mathrm{m}}$ (PEP), but, in contrast to the present case, concomitant increases in $V_{\max }$ were also observed when much higher PEP concentrations were employed (Paglia et al, 1968; Tanaka, 1969; Ohyama et al, I969; Boivin et al, 1969). Additionally distinctive, FDP activation in two of these families did not significantly affect $V_{\mathrm{max}}$, but converted $K_{\mathrm{m}}$ (PEP) to virtually normal values (Tanaka, I969; Paglia \& Valentine, I97I). In another family recently restudied by Munro \& Miller (1970) the kinetic anomaly was exaggerated by FDP activation, and reaction rates were a dependent variable of PEP concentration over such a broad range that satisfactory measurements of $V_{\max }$ were not possible in the presence of the activator. The peculiarities of the latter observations may have been partially an effect of enzyme purification procedures, since these are known to alter kinetic and reaction characteristics for erythrocyte $\mathrm{PK}$ in some instances (Wiesmann \& Tönz, I966; Boivin \& Galand, I968).

Perhaps more comparable to the present case are those reported by Waller \& Löhr (1964) and by Löhr et al (I968). In the former, $K_{\mathrm{m}}$ (PEP) was noted to be two to four times greater than normal in two cases, but $V_{\max }$ was less than $10 \%$ of normal mean. The family in the latter study was found to have a similar elevation in $K_{\mathrm{m}}$ (PEP), but the affected proband had a $V_{\max }$ approximating $40 \%$ of normal. Electrophoretic variations were also noted, but FDP activation analyses were not performed.

Mentzer \& Alpers (1971) have also studied cases of elevated $K_{\mathrm{m}}$ (PEP) partially corrected by FDP and coexisting with either normal or decreased PK activities, but details of these investigations are not yet available.

Much of the difficulty in deciding which of all these cases represent truly distinct isoenzymes, and which may be identical, is due to considerable variation in assay techniques. While many investigators have employed crude haemolysates in their studies, others have used preparations partially purified by a variety of methods, and it is apparent that purification procedures in themselves can variably alter kinetic qualities of erythrocyte PK. Nonetheless, it is clear that diverse mutant forms of this enzyme do exist, and, since they all accompany a common clinical syndrome, they provide strong evidence to support a basic pathophysiologic role for glycolytic enzymopathies in the induction of premature haemolysis. 


\section{ACKNOWLEDGMENTS}

These studies were supported in part by grants from the United States Public Health Service, the Veterans Administration, and the Leukemia Research Foundation of Los Angeles.

The patients were kindly referred by Dr Ruth M. Heyn and Dr Mary Ann Roloff of the Department of Pediatrics, University of Michigan Medical School.

The authors are indebted to Klaus Kürschner, Anneliese Merlino, and Ernesto Guereque for additional technical contributions and to Sharon DeBenedet for assistance with the manuscript.

\section{REFERENCES}

Baughan, M.A., Valentine, W.N., Paglia, D.E., Ways, P.O., Stmons, E.R. \& DeMarsh, Q.B. (I968) Hereditary hemolytic anemia associated with glucosephosphate isomerase (GPI) deficiency-a new enzyme defect of human erythrocytes. Blood, 32, 236.

Borvin, P. \& Galand, C. (I968) Recherche d'une anomalie moléculaire lors des déficits en pyruvate kinase érythrocytaire. Nouvelle Revue Franfaise d'Hématologie, 8, 201.

Botvin, P., Galand, C., Mallarme, J. \& Perrot, R. (1969) Mise en évidence d'un enzyme a cinétique anormale dans deus nouveaux cas de déficit en pyruvate-kinase érythrocytaire. Pathologie et Biologie, I7, 597 .

Bücher, T. \& Pfleiderer, G. (1955) Pyruvate kinase from muscle. Methods in Enzymology (Ed. by S. P. Colowick and N. O. Kaplan), Vol. I, p 435. Academic Press, New York.

Kertr, A.S. (1966) Pyruvate kinase deficiency and related disorders of red cell glycolysis. American Journal of Medicine, 41, 762 .

Koutras, G.A., Hattorr, M., Schnemder, A.S., Ebaugh, F.G., JR \& Valentine, W.N. (I964) Studies on chromated erythrocytes. Effect of sodium chromate on erythrocyte glutathione reductase. Joumal of Clinical Investigation, 43, 323.

KRIMSKY, I. (1963) D-2,3-Diphosphoglycerate. Methods of Enzymatic Analysis (Ed. by H.-U. Bergmeyer), p 238. Academic Press, New York.

LöHR, G.W., Blume, K.G., Rüdiger, H.W., SoKal, G. \& GuLBIS, E. (1968) A new type of pyruvatekinase deficiency of human erythrocytes. (Letter). Lancet, i, 753 .

MENTZER, W. \& Alpers, J. (r97I) Mild anemia with abnormal RBC pyruvate kinase. (Abstract). Clinical Research, 19, 209.

Minakami, S., Suzuki, C., Sarro, T. \& Yoshikawa, H. (1965) Studies on erythrocyte glycolysis. I. Determination of the glycolytic intermediates in human erythrocytes. Joumal of Biochemistry, 58, 543 .

MunRo, G.F. \& MILLER, D.R. (1970) Mechanism of fructose diphosphate activation of a mutant pyruvate kinase from human red cells. Biochimica et Biophysica Acta, 206, 87.

Ohyama, H., Kumatori, T., Nishina, T. \& Mrwa, S. (I969) Functionally abnormal pyruvate kinase in congenital hemolytic anemia. Acta Haematologica Japonica, 32, 330.

Pagila, D.E. \& Valentine, W.N. (1967) Studies on the quantitative and qualitative characterization of erythrocyte glutathione peroxidase. Journal of Laboratory and Clinical Medicine, 70, is8.

Paglia, D.E. \& Valentine, W.N. (I97I) Additional kinetic distinctions between normal pyruvate kinase and a mutant isozyme from human erythrocytes. Correction of the kinetic anomaly by fructoseI,6-diphosphate. Blood, 37, 31 I.

Paglia, D.E., Valentine, W.N., Baughan, M.A., Muler, D.R., REed, C.F. \& MClNTYRe, O.R. (I968) An inherited molecular lesion of erythrocyte pyruvate kinase. Identification of a kinetically aberrant isozyme associated with premature hemolysis. Journal of Clinical Investigation, 47, 1929.

Schnemer, A.S., Valentine, W.N., Hattori, M. \& Henss, H.L., JR (I965) Hereditary hemolytic anemia with triosephosphate isomerase deficiency. New England Journal of Medicine, 272, 229.

SELWYN, J.G. \& DACIE, J.V. (1954) Autohemolysis and other changes resulting from the incubation in vitro of red cells from patients with congenital hemolytic anaemia. Blood, 9, 414.

Tanaka, K.R. (I969) Pyruvate kinase deficiency hereditary hemolytic anemia. Japanese Journal of Gentetics, 44, Suppl. I. 286.

Tanaka, K.R. \& Paglia, D.E. (I97I) Pyruvate kinase deficiency. Seminars in Hematology, 8, 367 .

Tanaka, K.R. \& Valentine, W.N. (r968) Pyruvate kinase deficiency. Hereditary Disorders of Erythrocyte Metabolism (Ed. by E. Beutler), p 229. Grune \& Stratton, New York.

Valgintine, W.N., Hsieh, H.-S., Paglia, D.E., ANDERSON, H.M., BaUghaN, M.A., JafFé, E.R. \& GARSON, O.M. (1969) Hereditary hemolytic anemia 
associated with phosphoglycerate kinase deficiency in erythrocytes and leukocytes. New England Joumal of Medicine, 280,528 .

Valentine, W.N., Oski, F.A., Paglia, D.E., Baughan, M.A., Schnemer, A.S. \& NaLman, J.L. (1967) Hereditary hemolytic anemia with hexokinase deficiency. Role of hexokinase in erythrocyte aging. New England Journal of Medicine, 276,1 .

Valentine, W.N., Paglia, D.E., Neerhout, R.C. \& KonRaD, P.N. (1970) Erythrocyte glyoxalase II deficiency with coincidental hereditary elliptocytosis. Blood, 36, 797.

Valentine, W.N. \& Tanaka, K.R. (I966) Pyruvate kinase: clinical aspects. Methods in Enzymology (Ed. by S. P. Colowick, N. O. Kaplan and W. A.
Wood), Vol. IX, p 468. Academic Press, New York.

WALLER, H.D. \& LÖHR, G.W. (1964) Hereditary nonspherocytic enzymopenic hemolytic anemia with pyruvate kinase deficiency. Proc. IX Congress of the International Society of Hematology, Mexico City, Vol. I, p 257. Universidad Nacional Autónoma de México.

Wiesmann, U. \& Tönz, O. (I966) Investigations of the kinetics of red cell pyruvate kinase in normal individuals and in a patient with pyruvate kinase deficiency. Nature, 209, $6 \mathrm{I} 2$.

ZuElzer, W.W., Robinson, A.R. \& Hsu, T.H.J. (I968) Erythrocyte pyruvate kinase deficiency in non-spherocytic hemolytic anemia: a system of multiple genetic markers? Blood, 32, 33 . 